\title{
Arts and science in Italy: from high schools to CERN
}

\author{
Pierluigi Paolucci $a, *$, Francesca Scianitti ${ }^{b}$ and Giuliana Galati, $c$ \\ a Istituto Nazionale di Fisica Nucleare di Napoli, \\ Complesso Universitario di Monte Sant Angelo Edificio 6, 80129 Napoli, ITALY \\ E-mail: pierluigi.paolucciena.infn.it
}

b Istituto Nazionale di Fisica Nucleare Ufficio Comunicazione,

Piazza dei Caprettari 70, 00186 Roma, Italia

E-mail: francesca.scianitti@presid.infn.it

c Università di Bari Aldo Moro e INFN Bari,

Via Giovanni Amendola, 70126 Bari, Italia

E-mail: giuliana.galati@uniba.it

Creativity and vision capability are common to many disciplines and are involved in artistic and scientific thinking and activities. Scientists and artists are often asked to see and think beyond the perceivable reality, to imagine aspects of things and events, which can be better seen from an unusual perspective. "Art \& Science across Italy" [1] is a European science communication project lead by the Italian National Institute for Nuclear Physics (INFN) in collaboration with CERN. The main idea is to put in practice the basic concept of the STEAM field in which neither STEM nor arts are privileged over the other, but both are equally in play. Therefore, our aim is to engage high school students with science using artistic languages, regardless of students' specific skills or level of knowledge.

Aspiring to create an informal learning environment conducive to nurturing creativity, inquiry and enjoyment in science learning, the project is premised on the view that, since "science is an activity that involves creativity and imagination as much as many other human activities", arts-based activities may constitute a suitable approach towards integrating creativity, imagination, and science in school settings. The project is now running the third edition (2020-2022). Here we will describe the methodology used, how the project is structured, and some results obtained in the first two editions in which more than 7.500 students coming from about 200 Italian high schools participated.

The Ninth Annual Conference on Large Hadron Collider Physics - LHCP2021

7-12 June 2021

Online 


\section{Introduction}

The basic idea inspiring Art \& Science Across Italy (A\&S), a project organized and funded by the Italian National Institute for Nuclear Physics (INFN) and by CERN, is to use art as universal language to address all students and talk about science, regardless of their knowledge and initial attitude towards scientific subjects, engaging and challenging them to represent scientific ideas and research topics through artworks. Any sort of artistic language can be used: painting, sculpture, photography, filmmaking, storytelling, or any other form of Art.

Which color is the Higgs boson? By virtue of their imagination, high school students are much better off than many researchers in answering that question, which is a call to unveil the emotional connection to physics and to science in general. By challenging their creativity and enabling them to have their say, we can engage students, catch their attention, bring them to ask questions, look at documentation, discover what the Higgs boson is about and why it is important to them.

The A\&S project was born in 2015 from an idea of P. Paolucci (INFN Naples), M. Hoch (HEPHY, Wien) and A. Alexopoulos (CERN). Initially it developed in the framework of the European network CREATIONS (H2020) [2] and it is inspired by the STEAM [3,4,5] educational frame-work which brings Science, Technology, Engineering and Mathematics together with Art, with the goal of being more engaging, creative and naturally successful for all members of any educational system.

\section{Description of the project}

The A\&S project takes place in many Italian Regions and it is addressed to high school students in the third and fourth year of their studies (15-18 years old) [6].

It is supervised by the INFN national scientific committee and organized by a coordination committee, composed by scientists from the regions where the project takes place. In each city the local coordinators keep the contacts with the high school institutes wishing to participate. A close collaboration with school institutes is of primary importance for the successful development of the program, which lasts 2 years and can be chronologically divided into the following phases:

Education phase: This phase has a duration of about 8 months. Students take part in outof-school activities and are invited to attend science lectures, to visit laboratories, Universities, scientific and art centers, art museums and local events. During this phase students meet and interact with scientists, science educators and communicators, as well as professional artists and art educators, and get exposed to out-of-school inspiring and interdisciplinary settings. Students are then encouraged and stimulated to ask questions and engage in dialogues that help them conceptualize similarities and differences in the way that creativity is viewed and employed during the scientific and artistic process respectively.

Creative phase: The second phase is structured around project-based learning. Students are invited to form teams of three, then they work to conceive, design and create an artwork inspired by a scientific topic of their choice. Any artistic technique is welcome: pictures, sculpture, jewel, photo, animation/movie, music, book, electronics and more. There are no restrictions or boundaries to their creativity.

Exhibition. The third phase consists of the dissemination of student's works through the organization of local exhibitions in collaboration with INFN institutes, local educational 
authorities and other stakeholders such as municipalities. The inclusion of a competition element is supported by evidence suggesting a positive association between student participation in STEM competitions. All the artworks are exhibited in the regional exhibition, and the first seven ranked access to the National competition. An international jury of experts, selected from both art and science world, selects the best 10 artworks and their authors are awarded with a fellow to participate to the Art \& Science master at CERN/INFN laboratory.

\section{Methods and key points}

The main goal of the project is to bring science and high school students closer together and the methodology used is founded on the following five key points.

Creativity: The project has been designed to stimulate the creativity of all students, without considering their scores at school or their interest in science. Both science and art are the triggers used to bring out the creativity of the next generations.

Science communication: During the education phase students have the possibility to see how the scientific research is done at university or in science centers. Physics, chemistry, biology, medicine and many other fields are shown to students exploiting the possibilities of each Italian region.

Work in team: Some of the pillars of the scientific research are: to work in team, to collaborate, to share ideas and personal skills. For this reason, the project requires working groups and it was decided to ask for three people per team in order to ensure that all of them can contribute effectively.

Conceive, design and create a project: Students have to face all the necessary steps needed to produce an artwork and to expose it at a public exhibition. They are called to sketch ideas on paper, to manage the time needed for execution, to the material procurement, to set dimensions and transportation, to find the best way to expose it. For many students this is the first time in which they are asked to create a project from the design to the construction and for this reason this phase is considered very interesting and at the same time complicated by most of them.

Interdisciplinarity: Diverse sources of information and skills are involved in the creative process. The whole project aims at bringing students closer to science, generating an insight about the relation between art and science. It is an opportunity to break the mindset barrier which still today takes apart the respective methodologies and competences. Art and science are framed as two different means to inquiry and observe the world, which share common historical roots and both of which involve abstraction and creativity.

\section{Numbers and results from the first two edition}

More than 7.500 students coming from 200 high schools of 9 geographical Italian regions participated to the first two editions of the project (2016/2018 and 2018/2020).

$58 \%$ of the students are female, $62 \%$ are from scientific high school and $27 \%$ from art schools. The entire distribution about the school type is shown in figure 1.

About $70 \%$ of students were able to produce the artwork and arrive to the end of the project, that confirms how difficult the "creative phase" is. 

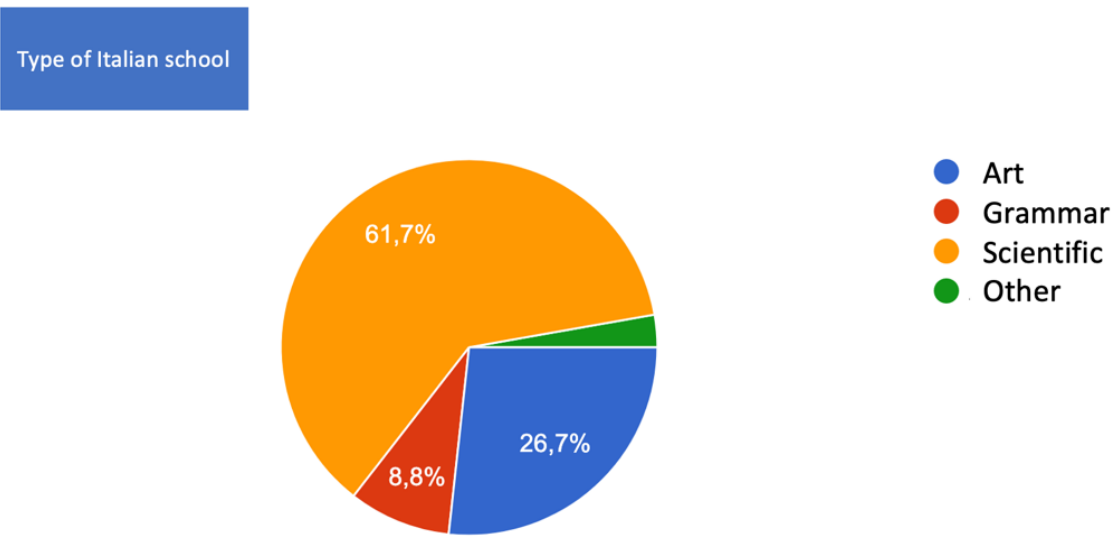

Fig.1: Type of high school of the students participating to the first two editions (2016-2020)

All the artworks have been shown in the local exhibitions. Three of them and the National exhibition have been done online due to COVID-19 restrictions.

The main results obtained from the post-questionnaire given to students are that $88 \%$ of students like the project, $92 \%$ would recommend it to a friend and about $73 \%$ enjoyed creating the artwork and show it at a public exhibition. It was clear since the beginning and confirmed by the questionnaire submitted to the 130 winners of the local competitions of the $1^{\text {st }}$ edition, that the creative process is very difficult (figure 2, right). The work in group was not a problem for most of them (figure 10, left).
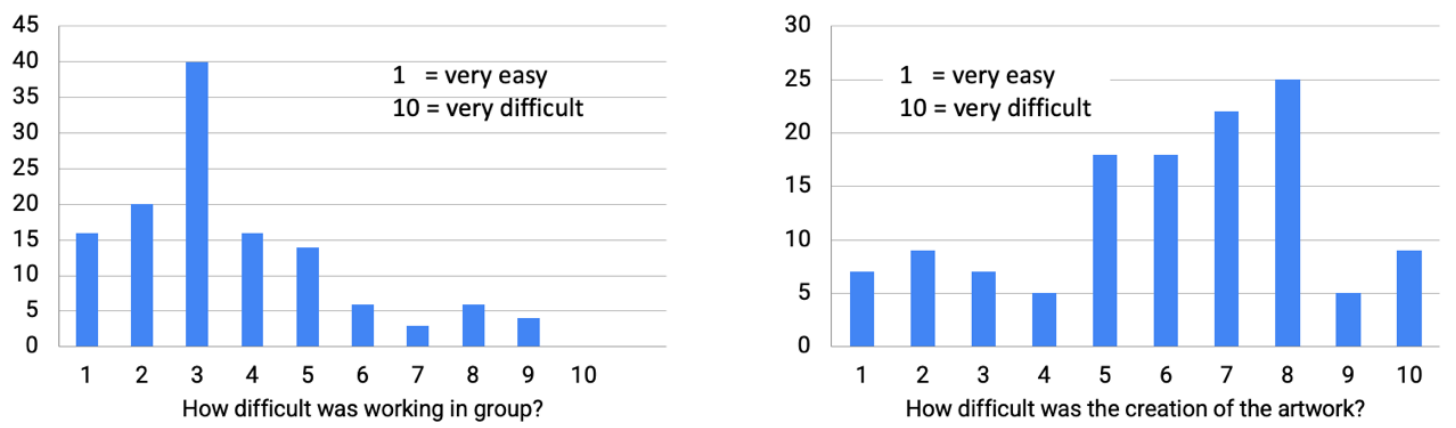

Figure 2: Results from the questionnaire submitted to the 130 local winners of the I edition. 125 students answered. How difficult was; work in group (left) and create the artwork (right)?

\section{References}

[1] The Art \& Science Across Italy project

Home Page URL: https://web.infn.it/artandscience

Facebook page. URL: https://www.facebook.com/artandscienceacrossitaly/

Instagram page. URL: https://www.instagram.com/artandscienceacrossitaly/ 
[2] CREATIONS European Project. URL: http://creations-project.eu.

[3] Conradty, C., \& Bogner, F. X. (2018). From STEM to STEAM: How to monitor creativity. Creativity Research Journal, 30(3), 233-240.

[4] Hunter-Doniger, 2018 (2018). Art infusion: Ideal conditions for STEAM. Art Education, 71(2), 2227.

[5] ATLAS and CMS Collab. (P. Paolucci et al.) STEAM: Education and Communication with Art at ATLAS and CMS; PoS LHCP2016 (2016) 115; DOI: 10.22323/1.276.0115

[6] S. Paoletti and P. Paolucci, (2020). Art as a language to represent Science: a project for Lyceum, PoS EPS-HEP2019 (2020) 456 